\title{
Article \\ Development of Jasmine Rice Flour Properties as a Safe and Efficient Ingredient for Compact Powder
}

\author{
Suekanya Jarupinthusophon ${ }^{1}\left(\mathbb{D}\right.$ and Oraphan Anurukvorakun ${ }^{2, *}$ \\ 1 Department of Chemistry, Phranakhon Rajabhat University, Bangkok 10220, Thailand; suekanya@pnru.ac.th \\ 2 Department of Cosmetic Science, Phranakhon Rajabhat University, Bangkok 10220, Thailand \\ * Correspondence: oraphan@pnru.ac.th; Tel.: +66-94-556-8638
}

Citation: Jarupinthusophon, $\mathrm{S}$

Anurukvorakun, O. Development of Jasmine Rice Flour Properties as a Safe and Efficient Ingredient for Compact Powder. Appl. Sci. 2021, 11, 248. https://doi.org/10.3390/app 11010248

Received: 11 November 2020 Accepted: 19 December 2020 Published: 29 December 2020

Publisher's Note: MDPI stays neutral with regard to jurisdictional clai$\mathrm{ms}$ in published maps and institutional affiliations.

Copyright: (C) 2020 by the authors. Licensee MDPI, Basel, Switzerland. This article is an open access article distributed under the terms and conditions of the Creative Commons Attribution (CC BY) license (https:// creativecommons.org/licenses/by/ $4.0 /)$.

\begin{abstract}
Natural flour is usually not used directly in compact powder since there are some drawbacks, such as roughness and poor skin adhesion. The purpose of this research was to investigate the extraction and modification of jasmine rice flour using polyethylene glycol (PEG)-50 shea butter. The physical properties in terms of flowability and water resistance of the modified rice flour were investigated and compared with talcum. The modified rice flour was used as the ingredient to develop the compact powder by replacing talcum, which is the main ingredient in compact powder that provides the slipperiness and spread properties, but it is quite harmful. The results of this research revealed that the physical properties of the modified powder changed in terms of flowability and water-resistance by PEG-50 shea butter. The modified rice flour provided better physical properties compared to non-modified rice powder. The modified rice powder, a safe ingredient, could replace $100 \%$ talcum in the developed compact powder. Furthermore, the developed compact powder provided Sun Protection Factor (SPF) greater than 15, or 93\%, UVB protection, good coverage with a natural appearance, smoothness, diffusion, softness of the skin, and a higher satisfaction level compared with the commercial product.
\end{abstract}

Keywords: jasmine rice flour; compact powder; PEG-50 shea butter

\section{Introduction}

Cosmetic powder has been used since ancient times. Generally, these products are marketed in the form of loose or compact powders (compression type). They are used to provide adhesion, smoothness, slipperiness, and some special effects on the skin [1,2]. Cosmetic powder products contain ingredients like fillers (e.g., talcum, kaolin, calcium, silica, silicates, magnesium carbonate, and metallic stearates), colors (e.g., pigments, bismuth oxychloride, lakes, and mica), perfume, preservatives, and binding agents (e.g., mineral oils, fatty esters, emulsifying agents, and lanolin). The composition of these ingredients, along with their particle size and physical properties (e.g., adhesive character, slipperiness, and water-resistance), impacts the technical quality of the final powder formulation $[1,3]$.

Talcum, the main ingredient in cosmetic powder, provides concealment, slipperiness, spread-ability, and smoothness, but talcum is usually discovered near asbestos. A scientific report revealed that talcum powder could increase the risk of cancer based on the relationship between the occupational groups exposed by ingestion or inhalation of asbestos in talcum [4]. Talcum is a non-biodegradable irritant that might stimulate cancer. Using natural flour, a biodegradable material, would be a challenge and an opportunity to overcome the risk.

Jasmine rice is one of the most important global food sources. Rice extracts and rice flour have many uses, even in cosmetics, since they contain high levels of phenolic compounds that are known to be bioactive, some of which provide cutaneous benefits and activity toward skin disorders. The main chemical component found in rice is carbohydrates $(70 \%)$ and the second component is a protein (usually found 7-9\%) [5]. There is also 
a small amount $(<5 \%)$ of fat and ash found in rice. Flour presents different chemical compositions because of differences in species growth conditions (such as soil and weather) and rice flour processing [6]. Carbohydrates from rice consist of flour, cellulose, hemicellulose, as well as sugar (sucrose) [7-10]. The main components found in flour are amylose and amylopectin. Rice protein consists of glutelins (80\%), albumins (5\%), globulins $(10 \%)$, and prolamins (5\%) [11]. Jasmine rice panicle extract, having high levels of phenolics, shows cutaneous benefits as the basis for skin ageing treatments, as indicated through in vitro cytotoxicity assessments and skin testing in human subjects [12,13].

Thus, jasmine rice flour would be a suitable ingredient for developing a compact powder. However, natural flour has some drawbacks in terms of roughness [14], poor skin adhesion, and poor water resistance. Therefore, rice flour needs some modification before application to compact powder. Polyethylene glycol (PEG)-50 shea butter is a polyethylene glycol derivative with an average of 50 moles of ethylene oxide. It is water-soluble whole shea butter made by a patented process [15]. This process maintains the well-known attributes of shea butter. It could be easily formulated into water-based products, such as shampoos, conditioners, creams, lotions, and other products.

The ultimate goals of this research were to develop a safe compact powder from modified rice flour using PEG-50 shea butter.

\section{Materials and Methods}

\subsection{Jasmine Rice Flour Preparation}

The jasmine rice in this study was purchased from Ying Charoen Trading, Khaosan Parn Lan Sub-district, Phayakkhaphum Phisai District Maha Sarakham Province, Thailand, harvested during May 2019. A slightly modified method of wet milling [16] was used to get the rice flour. Approximately $1 \mathrm{~kg}$ of rice was soaked in $1 \mathrm{~L}$ of distilled water before grinding using Moulinex to obtain rice slurry. The slurry was filtered through a filter bag to get the rice solution. The water was then left at room temperature for $5 \mathrm{~h}$, after which it was placed into the refrigerator for $24 \mathrm{~h}$ to obtain the rice flour that settled below by separating the water. The rice flour was dried in a tray dryer at $40^{\circ} \mathrm{C}$ for $2 \mathrm{~h}$ and the dried rice flour was ground and sieved through a 100-mesh sifter. The flour sample was packed in polypropylene plastic bags and stored in a desiccator at room temperature for further use and modification [17].

\subsection{Modification of Rice Flour with PEG-50 Shea Butter}

The proper dispersion of powder should possess covering properties to hide blemishes present on the skin. Additionally, it should possess a slippery property for easy spreading using a puff without creating any spots. Therefore, rice flour needs some modifying in terms of size, roughness, water-resistance, and skin adhesion before applying to compact powder.

Rice flour was soaked in distilled water (ratio of flour to water of 1:20) to obtain rice slurry for the aqueous phase before modifying with the PEG-50 shea butter. Rice flour was modified using 10\% PEG-50 shea butter for the PEG-50 shea butter phase. Then, the PEG-50 shea butter phase was gradually poured into the aqueous phase containing rice slurry and blended using a mixer at a speed of 10,000 rpm for $10 \mathrm{~min}$, then centrifuged at $5000 \mathrm{rpm}$ for $5 \mathrm{~min}$ to obtain the white pellets again. The modified rice flour was dried in a tray dryer at $40{ }^{\circ} \mathrm{C}$ for $2 \mathrm{~h}$. After that, the dried rice flour was ground and sieved through a 100-mesh sifter. The modified flour sample was packed in polypropylene plastic bags and stored in a desiccator at room temperature for further use. Before using the flour to formulate the compact powder, the flour was sterilized at $125^{\circ} \mathrm{C}$ for $30 \mathrm{~min}$.

\subsection{Chemical Property Analysis Using Fourier Transform Infrared Spectroscopy (IR)}

The transitions between the vibrational states of a molecule were observed experimentally via IR spectroscopy. IR vibrational spectroscopy provides information about 
the nature of the chemical bond, intramolecular forces running between the atoms in a molecule, and intermolecular forces.

Functional groups in the flour absorb IR energy at wavelengths characteristic of the particular groups and lead to changes in the vibrational modes within the functional groups. Therefore, through the infrared absorption characteristics of this flour, specific functional groups were identified. The functional groups between the modified flour and non-modified flour were studied and compared using IR (Fourier transform infrared spectrophotometer (FT-IR), Bruker Biospin AG, Ettlingen, Germany).

\subsection{Physical Properties Analysis of the Rice Flour}

\subsubsection{Flow-Ability}

Flow-ability was evaluated because it is one factor that affects the uniformity of the product unit. The flow-ability study of rice flour following the pharmacopoeia was used to determine the angle of repose. The angle of repose is the constant, three-dimensional angle (relative to the horizontal base) assumed by a clonelike pile of material formed. The simplest method for the determination of the angle of repose is the poured angle.

The rice flour was carefully poured through the funnel to avoid blockage to the funnel, fixed to the burette at the height of $4 \mathrm{~cm}$, and a graph paper was placed below the funnel on the table.

The height and radius of the pile were measured. The angle of repose of the rice powder was calculated using the formula as follows.

$$
\text { Angle of repose }(\theta)=\tan ^{-1}(\mathrm{~h} / \mathrm{r})
$$

where $h$ is the height of the pile and $r$ is the radius of the pile.

When the angle of repose is less than 25 degrees, the flow is said to be excellent. If the angle of repose is more than 40 degrees, the flow is considered to be poor, and when the angle of repose exceeds 50, the flow is rarely acceptable for manufacturing purposes [18].

\subsubsection{Water-Resistance}

In general, a water-resistant product may have a film or membrane as its watertight feature. Therefore, these tests are usually bundled together for a high-quality product. The water resistance of rice flour was compared with talcum by weighing both $5 \mathrm{~g}$ of the flour and talcum, then pouring the substances into a beaker containing $10 \mathrm{~mL}$ of distilled water, then recording the floating time of each powder.

\subsection{Compact Powder Formulation}

The formulation strategy of compact powder was to use the combination of a base powder (absorbent, emollient, skin-conditioning, sunscreen agent, opacifying agent), a colorant, a perfume, a preservative, and a binder.

The base powder, color, and perfume were mixed uniformly. The mixture was then bound using a binder and blended until the proper plasticity of mass was attained and compressed by the Cosmetic Powder Pressing Machine (Charn InterTech, Bangkok, Thailand).

Formulations of the compact powder were prepared under different conditions to compare the compact powder properties of the talcum (F1) and rice flour replaced talcum (F2) compact powders.

\subsection{Pay-Off Test}

This test was approving the adhesive property of powders with the puff. This test was mainly performed on compact powders $[19,20]$.

\subsection{Breakage Test}

In this test, compact powders were allowed to fall on a wooden surface from a height of about 8-10 inches. This test was performed 2-3 times, and then we checked to see 
whether any breakage had occurred on the compact powder. If the compact powder remained unbroken, then it showed resistance for normal handling by users $[19,20]$.

\subsection{Concealment Testing}

Pork skin served as a proven model representing human skin. We used portions of skin from pigs destined for human consumption to test the experimental concealment cost-effectively. The pork skin was purchased from CP Freshmart. The pork skin was washed with tap water and dried with tissue paper. It was then set aside to dry and remove humidity to simulate human skin, and to be able to reach the tint of the desired color.

A brown eyebrow pencil was used to apply pigment to the pork skin to simulate a blemish on the face. A brown eyebrow pencil was tinted in circles of $0.5 \mathrm{~cm}$. The measured color difference before and after each $0.01 \mathrm{~g}$ powder puff application was measured in triplicate at each point and displayed to analyze the ability to hide the blemish or concealment. The colorimeter used in this work was Colorimeter CIELAB (D65, $8 \mathrm{~mm}, 0.08$ accuracy). The CIELAB expresses a color's lightness, red/green intensity, and yellow/blue intensity, as $L^{*}, a^{*}$, and $b^{*}$ values, respectively. These devices compute the intensity of light reflected from the skin and correlate with pigmentation and erythema.

\subsection{Determination of the In Vitro Sun Protection Factor (SPF)}

The determination of the in vitro SPF was slightly modified from the Siliva report [21]. The investigated powders were dissolved in methanol:water (6:4) and diluted to $150 \mu \mathrm{g} / \mathrm{mL}$. SPF measurements performed on a microplate reader (Synergy HT, Biotek, Winooski, VT, USA). The measurements were made by switching to a xenon flash lamp and a monochromator for wavelength selection. Scanning spectra of five whitening creams, in which SPF was standardized and sampled in the solution, were obtained by running from 320 to $290 \mathrm{~nm}$ (in $5 \mathrm{~nm}$ intervals). The UV absorbance of the whitening creams, in which was SPF standardized, was used as a standard whitening cream for the calculation of the correction factor (CF). The equation proposed by Mansur [22] was used to calculate the SPF values for whitening cream samples. Mansur's method is simple and easily reproducible.

$$
\mathrm{SPF}=\mathrm{CF} \times \sum_{290}^{320} \mathrm{EE}(\lambda) \times I(\lambda) \times \operatorname{abs}(\lambda)
$$

where CF is correction factor, determined by five whitening creams in which SPF was standardized; $E E(\lambda)$ is the erythemal efficiency spectrum; $I(\lambda)$ is the solar simulator spectrum as measured with a calibrated spectrometer; $\mathrm{EE}(\lambda) \times I(\lambda)=290-320 \mathrm{~nm}$ in $5 \mathrm{~nm}$ increments; and abs $(\lambda)$ is the spectrometer measure of the powder absorbance. The absorbance was taken in triplicate at each point. Table 1 shows the normalized values of the product function used in this research.

Table 1. The normalized product function used in the calculation of Sun Protection Factor (SPF) data.

\begin{tabular}{cc}
\hline Wavelength $(\mathbf{n m})$ & EE $\times$ I (Normalized) * \\
\hline 290 & 0.0150 \\
295 & 0.0817 \\
300 & 0.2874 \\
305 & 0.3278 \\
310 & 0.1864 \\
315 & 0.0839 \\
320 & 0.0180 \\
Total & 1.000 \\
\hline
\end{tabular}

* EE: erythemal efficiency spectrum; I: solar simulator intensity spectrum.

\subsection{Patch Testing}

The irritation was evaluated using patch testing. The researchers recruited 20 healthy adult volunteers with no underlying skin disease or skin lesions in the test area. Inclusion criteria were normal skin, no use of any anti-allergic or steroid medication, older 
than 18 years old, not pregnant, and not breastfeeding. Exclusion criteria were the use of a topical medication containing steroids to treat skin diseases and severe skin-related pathologies and abnormalities, such as erythema and eczema. All volunteers were informed of objectives, test procedures, and possible adverse effects and were rewarded for their participation. The Ethics Committee of Phranakhon Rajabhat University, Bangkok, Thailand approved the present method (AF05-06 study code: 62/105). All volunteers gave consent before entering the study. Volunteers had the right to withdraw from the test at any time without consequence or penalty.

During the patch test method, the developed powder was kept on the inside of the arm and in contact with the skin under a $2 \times 2 \mathrm{~cm}^{2}$ occlusive patch. After the required periods $(2 \mathrm{~h})$ of skin contact, the patches were opened and observed for any signs of skin irritation. The clinical observation of the effects was carried out after the withdrawal of the patch. The irritation signified ranking varies between not irritant, erythema, redness (transient), papules, or edema.

\subsection{Testing of Satisfaction}

To investigate the satisfaction of the products, 20 volunteers indicated their satisfaction using questionnaires. The five-rating scale questionnaire consisted of two parts: personal data, and product data. Questions in the personal data section were about sex, age, and type of skin. The questions concerning compact powder efficacy were about concealment, slipperiness, skin adhesion, color, spread, and skin softening. The five-rating scale used a scale that ranged from 1 (strongly dissatisfied) to 5 (strongly satisfied). Additionally, the developed product was compared to the satisfaction with the commercial product in the blinded experiment.

\section{Results}

\subsection{Jasmine Rice Flour Preparation}

The appearance of extracted rice flour was white powder. The powder had a fine texture and a slight stickiness to the skin. However, the smoothness of the powder was still not delicate compared to talcum. The percentage yield of jasmine rice flour extraction was approximately $33.42 \%$. The appearance of the modified rice flour with $10 \%$ PEG-50 shea butter was a smooth and soft white powder. It had better skin adhesion than undeveloped rice flour. The appearance of each powder is represented in Figure 1.

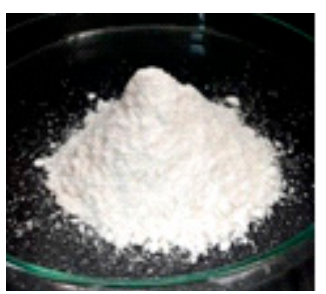

Rice flour

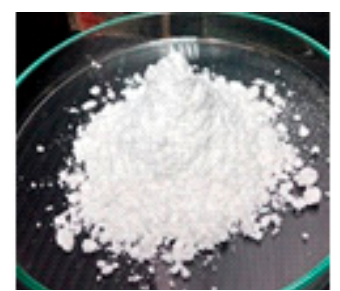

Modified of rice flour with $10 \%$ PEG-50 shea butter

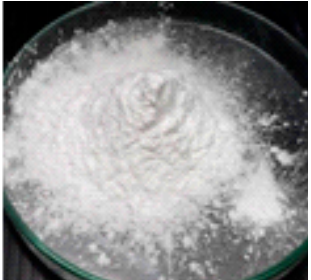

Talcum

Figure 1. The appearance of the powders.

\subsection{Chemical Property Analysis Using Fourier Transform Infrared Spectroscopy}

The transmission of infrared spectroscopy (IR) was performed at the wavenumber range of $400-4000 \mathrm{~cm}^{-1}$. Figure 2 reveals the IR spectrum of the non-modified rice flour, and PEG-50 shea butter. Figure 3 represents the IR spectrum of non-modified rice flour and modified rice flour. 

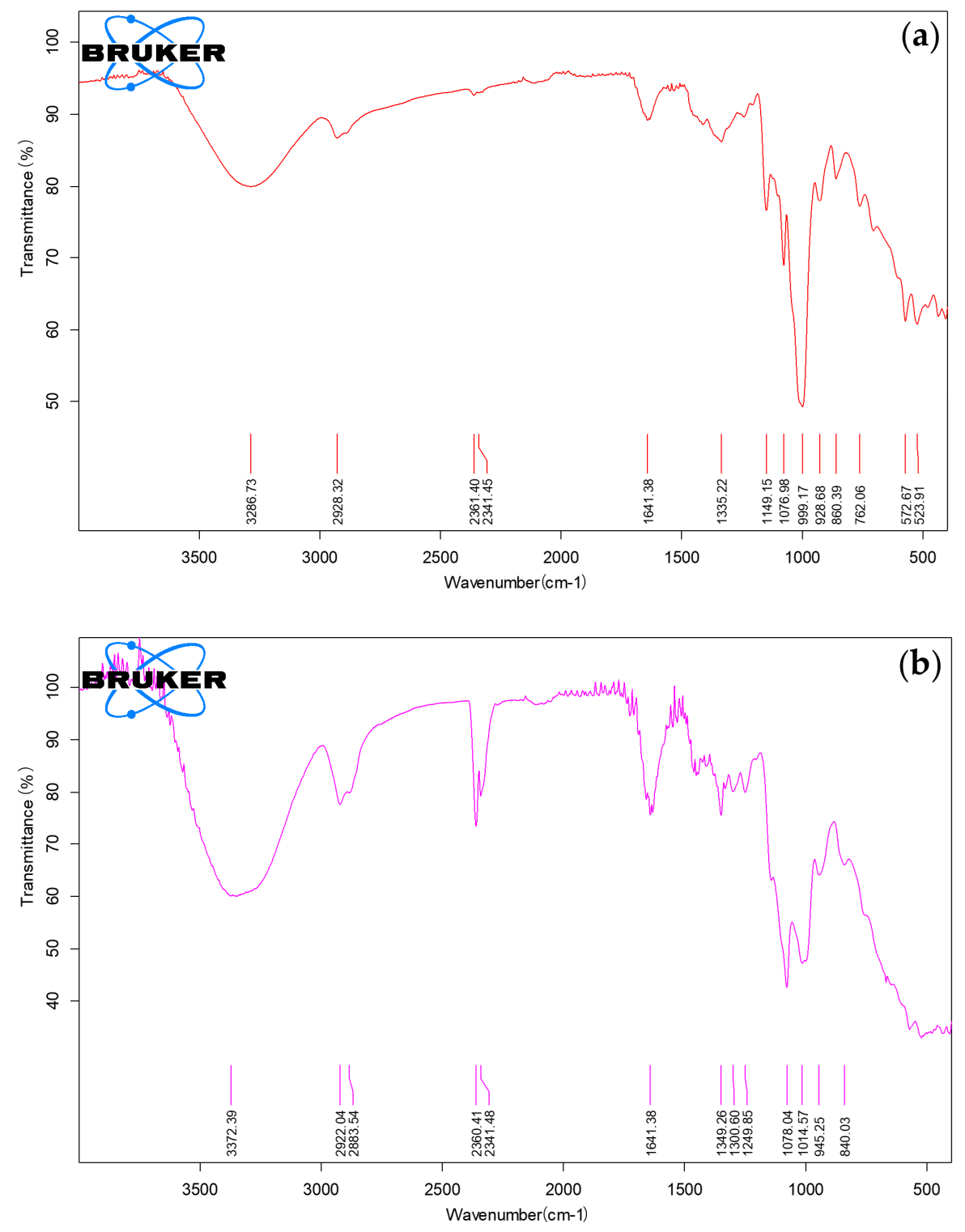

Figure 2. Illustrates the application of the Fourier transform infrared spectrophotometer (FT-IR) spectrum to, (a) the rice flour, (b) PEG-50 shea butter.

They similarly provided an IR spectrum in the wavelength range of $1150-1085 \mathrm{~cm}^{-1}$, which is likely the aliphatic ether absorption range or amylose.

Amylose is a polymer of glucose found in rice flour. Moreover, the IR spectrum range of $1640 \mathrm{~cm}^{-1}$ was assigned to lignin (hydrocarbon compounds in the cell wall such as cellulose, hemicellulose, and pectin). The major bands were located at 2925.48 and $2855.1 \mathrm{~cm}^{-1}$ corresponding to the asymmetric and symmetric stretch $\mathrm{C}-\mathrm{H}$ aliphatic, 2360.44 , and $2341.16 \mathrm{~cm}^{-1}$ corresponding to the asymmetric and symmetric stretch of atmospheric $\mathrm{CO}_{2}$ [23]. However, in the range of $999.17 \mathrm{~cm}^{-1}$, the IR spectrum presented slightly different details, which represents strong $C=C$ bending of the alkene group. The characteristics were compliant with PEG 50 shea butter spectrums in modified jasmine rice flour (Figure 3). 


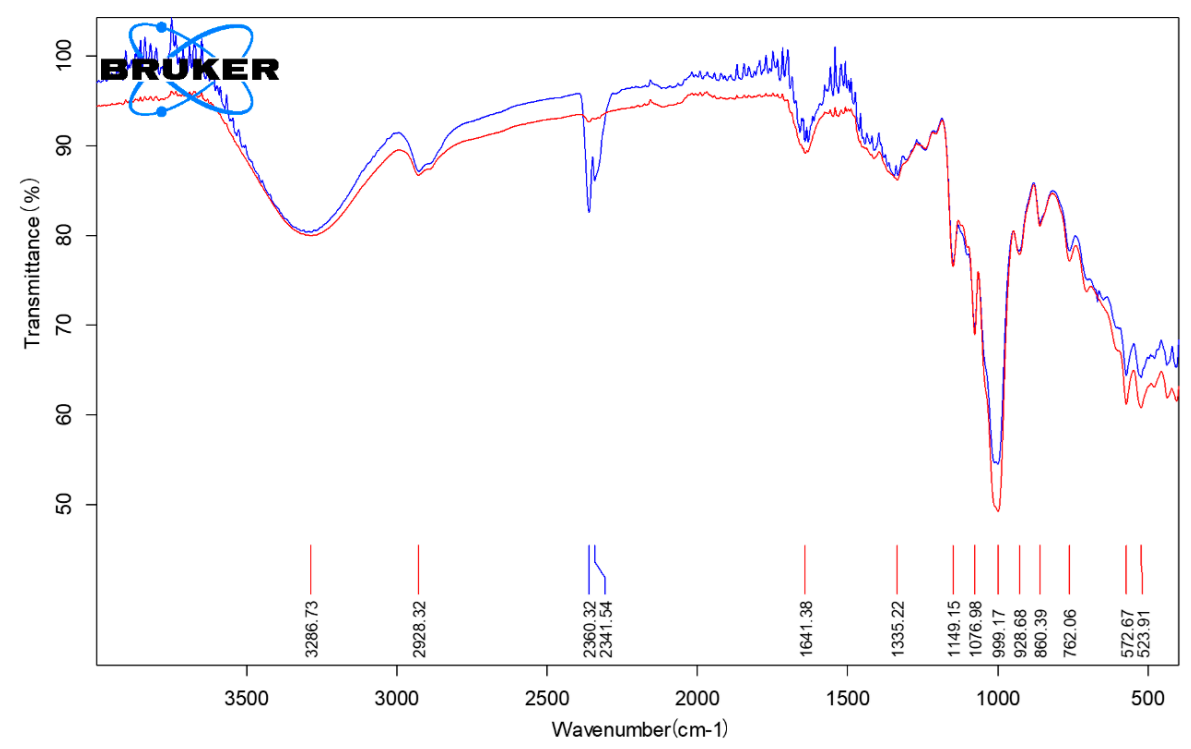

Figure 3. Overlay of the FT-IR spectrum of non-modified rice flour (red) and the spectra measured for modified rice flour (blue) in transmission mode.

\subsection{Physical Properties Analysis of the Rice Flour \\ 3.3.1. Flowability}

The results for the angle of repose of rice flour and modified rice flour with $10 \%$ PEG-50 shea butter were $50.65^{\circ}$ and $49.23^{\circ}$, respectively, while the angle of repose of talcum was $30.11^{\circ}$. The results showed that the flowability of the modified rice flour was better than non-modified rice flour.

\subsubsection{Water Resistance}

The water resistance revealed that talcum could stand longer in water than rice flour (50 $\mathrm{min}$ ). However, the modified rice flour could stand up to $5.24 \mathrm{~min}$ of water compared to non-modified rice flour, which could stand in the water for $1.02 \mathrm{~min}$.

\subsection{Compact Powder Formulation}

The acceptance criteria which were considered the measures of success for the developed compact powder were absorbency, slipperiness, concealment, skin adhesion, and ability to produce a transparency effect. The two compact powders, the talcum compact powder (F1) and the modified rice flour replaced talcum (F2), were successfully developed and are presented in Figure 4.

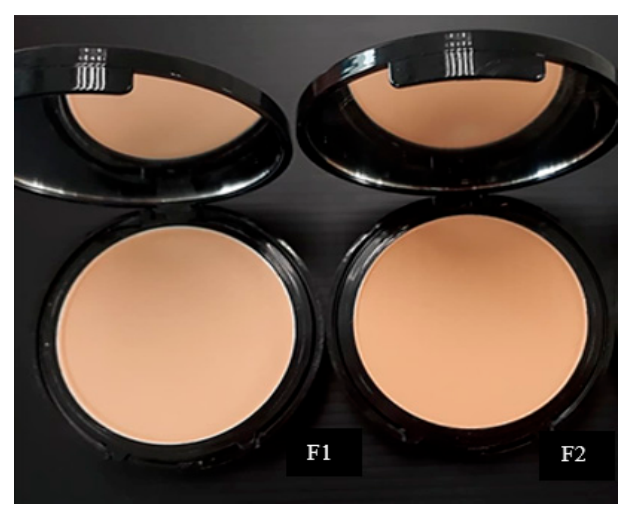

Figure 4. The appearance of the compact powders: the talcum compact powder (F1) and rice flour replaced talcum $(\mathrm{F} 2)$. 


\subsection{Pay-Off Test}

The adhesive property of the powders with the puff of the developed products was observed and we found that both products presented a highly adhesive property (Figure 5).

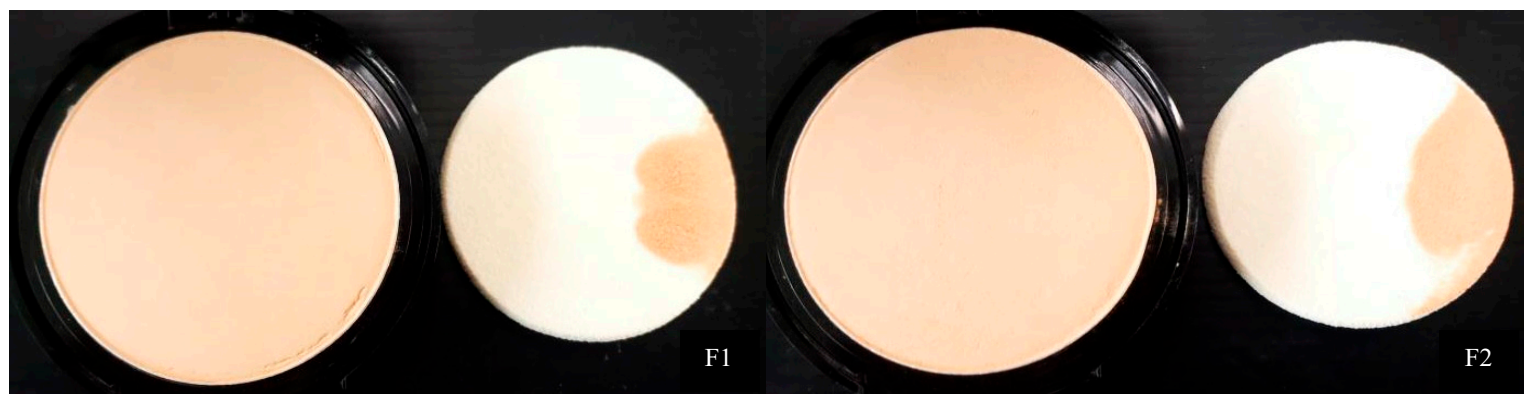

Figure 5. The appearance of the puffs for the pay-off test: the talcum compact powder (F1) and rice flour replaced talcum (F2).

\subsection{Breakage Test}

The adhesive property of powders with the puff of the developed products was observed and we found that both products presented a highly adhesive property (Figure 6). After drop testing, the talcum-compact powder (F1) and the modified rice flour compact powder (F2) slightly cracked under an optimum compressive strength of 10 bars, as shown in Figure 6.

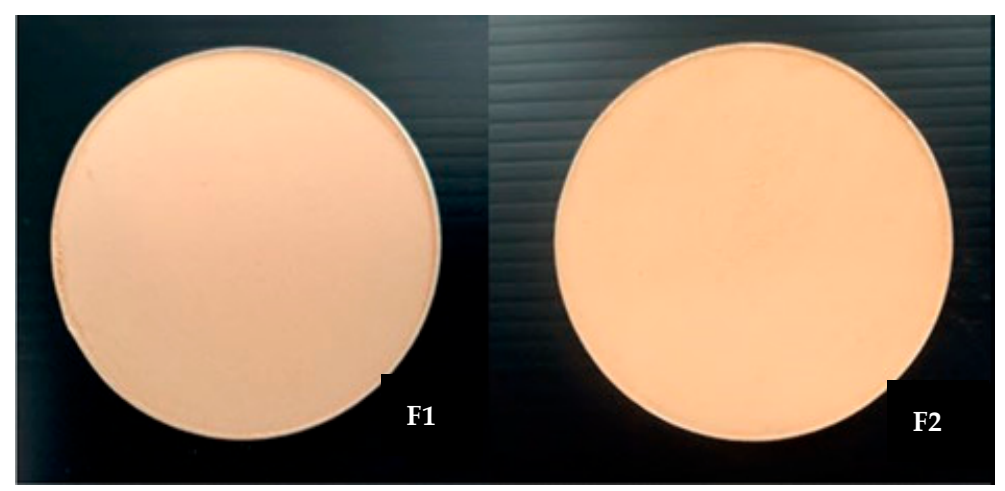

Figure 6. The appearance of the puffs for the breakage test: the talcum-compact powder (F1) and the modified rice flour replaced talcum (F2).

\subsection{Concealment Testing}

The difference measured in $\mathrm{L}^{*}$ values, which is the parameter representing lightness, was $17.11 \pm 5.86$ for the commercial product, which is a difference of 6.62 compared with the modified rice flour compact powder (F2). The $a^{*}$ values, which is the parameter representing redness, decreased as skin color became brighter, especially for the modified rice flour compact powder (F2). The modified rice flour compact powder (F2) provided the highest difference in $\mathrm{a}^{*}$ values of -1.33 . The difference measured in the $\mathrm{b}^{*}$ values, which is the parameter representing yellowness, was 4.53 for a commercial product, which is a difference of 2.32 compared with the modified rice flour compact powder (F2), as shown in Table 2.

The results revealed that the modified rice flour compact powder and the compact powders could conceal the blemish by increasing the brightness and yellowness and reducing the redness. Even though the modified rice flour compact powder (F2) provided the minimum lightness and yellowness, which is suitable for natural looks, this compact powder also conceals dark colors and redness the best. 
Table 2. Mean of color values (color's lightness $\left(\mathrm{L}^{*}\right)$, red/green intensity $\left(\mathrm{a}^{*}\right)$, yellow/blue intensity $\left(\mathrm{b}^{*}\right)$ ), before and after applying the compact powders, and the difference.

\begin{tabular}{|c|c|c|c|c|c|c|c|c|c|}
\hline \multirow{2}{*}{ Compact Powder } & \multicolumn{3}{|c|}{ Before Applying the Compact Powder } & \multicolumn{3}{|c|}{ After Applying the Compact Powder } & \multicolumn{3}{|c|}{$\begin{array}{c}\text { Difference in Values (After-Before } \\
\text { Applying the Powder) }\end{array}$} \\
\hline & $\mathbf{L}^{*}$ & $a^{*}$ & $\mathbf{b}^{*}$ & $L^{*}$ & $a^{*}$ & $\mathbf{b}^{*}$ & $\mathbf{L}^{*}$ & $a^{*}$ & $b^{*}$ \\
\hline $\begin{array}{l}\text { The talcum-compact } \\
\text { powder (F1) }\end{array}$ & $45.88 \pm 0.81$ & $8.62 \pm 0.10$ & $11.56 \pm 1.06$ & $62.81 \pm 0.87$ & $7.36 \pm 0.38$ & $13.87 \pm 1.29$ & $16.93 \pm 1.50$ & $-1.26 \pm 0.29$ & $2.31 \pm 1.93$ \\
\hline $\begin{array}{l}\text { The modified rice flour } \\
\text { compact powder (F2) }\end{array}$ & $47.97 \pm 1.61$ & $8.89 \pm 0.25$ & $10.47 \pm 0.59$ & $58.46 \pm 2.07$ & $7.56 \pm 0.22$ & $12.69 \pm 0.60$ & $10.49 \pm 0.64$ & $-1.33 \pm 0.26$ & $2.21 \pm 1.05$ \\
\hline Commercial product & $43.18 \pm 1.80$ & $8.45 \pm 0.17$ & $9.47 \pm 0.71$ & $60.30 \pm 3.27$ & $7.20 \pm 0.14$ & $14.01 \pm 2.06$ & $17.11 \pm 5.86$ & $-1.25 \pm 0.04$ & $4.53 \pm 3.12$ \\
\hline
\end{tabular}

Note: Number of experiments: 3: Data given in mean \pm SD.

\subsection{Determination of the In Vitro Sun Protection Factor}

Using the five whitening creams with standardized SPF, we calculated the correction factor using Equation (1). The final average correction factor was 46.57. The average correction factor was used to calculate SPF values. The SPF values of the different compact powders, (talcum-compact powder (F1), modified rice flour replaced talcum (F2), and the commercial product), were determined using a UV spectrophotometer as shown in Table 3.

Table 3. Absorbance of each compact powders used in the calculation of SPF data.

\begin{tabular}{cccc}
\hline Wavelength (nm) & $\begin{array}{c}\text { Talcum Compact } \\
\text { Powder (F1) }\end{array}$ & $\begin{array}{c}\text { Modified Rice Flour } \\
\text { Replaced Talcum (F2) }\end{array}$ & $\begin{array}{c}\text { Commercial } \\
\text { Compact Powder }\end{array}$ \\
\hline 290 & 1.140 & 1.143 & 1.117 \\
295 & 0.618 & 0.621 & 0.608 \\
300 & 0.374 & 0.377 & 0.368 \\
305 & 0.311 & 0.314 & 0.306 \\
310 & 0.283 & 0.285 & 0.278 \\
315 & 0.263 & 0.266 & 0.260 \\
320 & 0.235 & 0.244 & 0.235 \\
\hline
\end{tabular}

The SPF values of each powder were 16.59, 16.71, and 16.32 for the talcum-compact powder (F1), modified rice flour replaced talcum (F2), and the commercial product, respectively. The SPF analysis revealed that the developed compact powder does not provide much different sun protection effectiveness compared to the commercial compact powder. The SPF value of the compact powder was 16, which corresponds to a $93 \%$ UVB-protection [24].

\subsection{Patch Testing}

For the irritation evaluation, patch testing under the clinical observation and approved protocol of The Ethics Committee of Phranakhon Rajabhat University. Twenty volunteers aged from 18 to 22 years old were selected to participate in the irritation evaluation. The developed compact powder was used to investigate. Among the twenty volunteers, all volunteers experienced no skin irritation, redness (transient), or erythema, or experienced very slight irritation to the developed powder.

\subsection{Testing of Satisfaction}

The analysis of satisfaction toward the developed product (F2) provided the highest satisfaction level overall (concealment, slipperiness, skin adhesion, color, spread, and skin-softening). Averages of satisfaction with the developed product and the commercial product were 4.22 and 3.79, respectively, as shown in Figure 7. The paired samples $t$-test (SPSS; Version 23.0) indicated a statistically significant difference in the satisfaction between the developed product and a commercial product $(p<0.05)$ in terms of slipperiness, spread, and skin softening. When considering each aspect, the results indicated that the highest average value of the satisfaction was the spread (4.52), followed by the skin softening (4.40), slipperiness (4.24), skin adhesion (4.16), concealment (4.08), and color (3.92). 


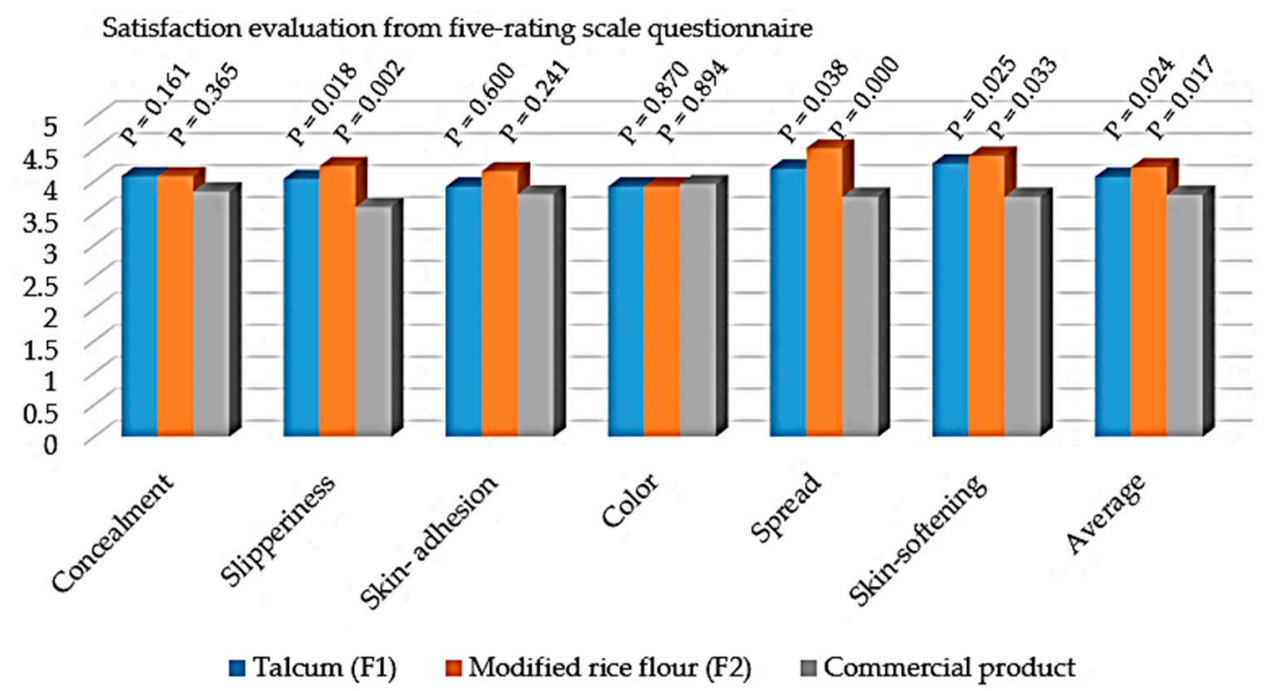

Figure 7. Bar graph of satisfaction with each powder: talcum compact powder (F1), modified rice flour replaced talcum (F2), and a commercial product; $p$-value from the paired samples $t$-test compared to the commercial product.

\section{Discussion}

This current study presented a safe and high-efficiency compact powder. The modified rice flour using $10 \%$ PEG-50 shea butter was successfully developed. The modified rice flour provided better physical properties in terms of flow-ability and water-resistance compared with the non-modified rice powder. For developing compact powder, the modified rice flour could $100 \%$ replace talcum.

The developed compact powder provided minimal lightness and yellowness, which is suitable for natural application; this powder also provided the best concealment of dark colors or redness.

The SPF analysis revealed that the developed compact powder (16.71) did not provide much different sun protection effectiveness compared with a commercial compact powder (16.32). Impressively, the results of this research revealed high SPF values compared with other natural products. The SPFs of methanol solutions of flowers of Calendula officinale and flowering tops of Hypericum perforatum are 12.01 and 12.21, respectively [25]. The SPF values of the products containing extracts from Mentha piperita (Leaves), Azadirachta indica (Leaves), Oscimum sanctum (Leaves), Aloe vera (Leaves), Lycopersicon esculentum (fruits), and Carica papaya (fruits) are 8.184, 4.368, 2.904, 5.437, 6.083, and 2.310, respectively [26].

Additionally, the overall satisfaction and the satisfaction in terms of slipperiness, spread, and skin-softening of developed rice compact powder was statistically higher than the commercial product.

In conclusion, the developed compact powder is a powder that does not easily break and contains natural flour (modified rice flour), a safe ingredient. Furthermore, the developed compact powder provided SPF, greater than 15 , or $93 \%$ UVB protection, good coverage with a natural appearance, smoothness, diffusion, and softness of the skin.

\section{Patents}

Anurukvorakun, O; Jarupinthusophon, S. Formulation and development process of rice flour with PEG-50 shea butter to replace talcum for compact powders. Th. Patent PT 073182, 14 September 2020.

Author Contributions: Conceptualization, O.A. and S.J.; methodology, O.A.; software, O.A.; validation, O.A., S.J.; formal analysis, O.A., S.J.; investigation, S.J.; resources, S.J.; data curation, O.A.; writing—original draft preparation, O.A.; writing—review and editing, O.A., S.J.; funding acquisition, O.A., S.J. All authors have read and agreed to the published version of the manuscript. 
Funding: This research was funded by the Phranakhon Rajabhat University Foundation, grant number 3-204-313-1901.

Institutional Review Board Statement: The Ethics Committee of Phranakhon Rajabhat University, Bangkok, Thailand approved the present method involving humans (AF05-06 study code: 62/105). Date of approval: 20 January 2020.

Informed Consent Statement: Informed consent was obtained from all subjects involved in the study. Data Availability Statement: The data presented in this study are available in this article.

Acknowledgments: The proposed experiments have been carried out in the Department of Cosmetic Science, Phranakhon Rajabhat University.

Conflicts of Interest: The authors declare no conflict of interest.

\section{References}

1. Farber, L. Cosmetic Science and Technology, 2nd ed.; Wiley: New York, NY, USA, 1972; pp. 335-353.

2. Moussour, M.; Lavarde, M.; Pensé-Lheritier, A.M.; Bouton, F. Sensory analysis of cosmetic powders: Personal care ingredients and emulsions. Internat. J. Cosmet. Sci. 2016, 39, 83-89. [CrossRef] [PubMed]

3. Chang, C.J.; Tu, Y.K.; Chen, P.C.; Yang, H.Y. Talc exposure and risk of stomach cancer: Systematic review and meta-analysis of occupational cohort studies. J. Formos. Med. Assoc. 2020, 119, 781-792. [CrossRef] [PubMed]

4. Thirumdas, R.; Deshmukh, R.R.; Annapure, U.S. Effect of Low Temperature Plasma on the Functional Properties of Basmati Rice Flour. J. Food Sci. Technol. 2016, 53, 2742-2751. [CrossRef] [PubMed]

5. Serna-Saldivar, S.O. Cereal Grains: Properties, Processing, and Nutritional Attributes; CRC Press: Boca Raton, FL, USA, 2016; 752p. [CrossRef]

6. Mir, S.A.; Bosco, S.J.D. Cultivar Difference in Physicochemical Properties of Floures and Flours from Temperate Rice of Indian Himalayas. Food Chem. 2014, 157, 448-456. [CrossRef] [PubMed]

7. Xia, W.; Fu, G.; Liu, C.; Zhong, Y.; Zhong, J.; Luo, S.; Liu, W. Effects of Cellulose, Lignin and Hemicellulose on the Retrogradation of Rice Starch. Food Sci. Technol. Res. 2014, 20, 375-383. [CrossRef]

8. Chaudhari, P.R.; Tamrakar, N.; Singh, L.; Tandon, A.; Sharma, D. Rice nutritional and medicinal properties: A review article. J. Pharmacogn. Phytochem. 2018, 7, 150-156.

9. Rohman, A.; Helmiyati, S.; Hapsari, M.; Setyaningrum, D.L. Rice in health and nutrition. Int. Food Res. J. 2014, 21 , 13-24.

10. Amagliani, L.; Regan, J.; Kelly, A.L.; Mahony, J.A. The Composition, Extraction, Functionality and Applications of Rice Proteins: A review. Trends Food Sci. Technol. 2017, 64, 1-12. [CrossRef]

11. Kanlayavattanakul, M.; Lourith, N.; Chaikul, P. Jasmine rice panicle: A safe and efficient natural ingredient for skin aging treatments. J. Ethnopharmacol. 2016, 193, 607-616. [CrossRef] [PubMed]

12. Maisuthisakul, P.; Changchub, L. Effect of Extraction on Phenolic Antioxidant of Different Thai Rice (Oryza Sativa L.) Genotypes. Int. J. Food Prop. 2014, 17, 855-865. [CrossRef]

13. Jan, S.; Ghoroi, C.; Saxana, D.C. Effect of particle size, shape and surface roughness on bulk and shear properties of rice flour. J. Cereal Sci. 2017, 76, 215-221. [CrossRef]

14. United States Patent Application Publication. Available online: https://patentimages.storage.googleapis.com/a5/49/f3/931c9 2d336c7f4/US20160008262A1.pdf (accessed on 30 September 2020).

15. Leewatchararongjaroen, J.; Anuntagool, J. Effects of Dry-Milling and Wet-Milling on Chemical, Physical and Gelatinization Properties of Rice Flour. Rice Sci. 2016, 23, 274-281. [CrossRef]

16. Varavinit, S.; Shobsngob, S.; Varanyanond, W.; Chinachoti, P.; Naivikul, O. Effect of amylose content on gelatinization, retrogradation and pasting properties of flours from different cultivars of Thai rice. Starch-Stärke 2003, 55, 410-415. [CrossRef]

17. Power Flow. Available online: https://www.usp.org/sites/default/files/usp/document/harmonization/gen-chapter/g05_pf_ 30_6_2004.pdf (accessed on 30 September 2020).

18. López, B.; Alejandre, F.J.; Alés, F.V. Methodology for characterising microlayers in historical plasterwork. Constr. Build. Mater. 2015, 93, 463-470. [CrossRef]

19. Mohiuddin, A.K. An extensive review of face powders: Functional uses and formulations. Int. J. Pharm. Pharm. Sci. 2019, 1, 1-12.

20. Sharma, G.K.; Gadiya, J.; Dhanawat, M. Evaluation of powders. In Textbook of Cosmetic Formulations; 2018; pp. 38-39. Available online: https: / / www.researchgate.net/publication/325023106 (accessed on 7 September 2020).

21. Siliva, V.V.D.; Ropke, C.D.; Almeida, R.L.D.; Miranda, D.V.; Kera, C.Z.; Rivelli, D.P. Chemical stability and SPF determination of extract gel and photostability of 4-nerolidylcathecol. Int. J. Pharm. 2005, 303, 25-31.

22. Mansur, J.S.; Breder, M.; Mansur, M.; Azulay, R.D. Determination of the sun protection factor by spectrophotometry. An. Bras. Dermatol. 1986, 61, 121-124.

23. Zhuang, J.; Li, M.; Pu, Y.; Ragauskas, A.J.; Yoo, C.G. Observation of Potential Contaminants in Processed Biomass Using Fourier Transform Infrared Spectroscopy. Appl. Sci. 2020, 10, 4345. [CrossRef]

24. United States Environmental Protection Agency, Sunscreen: The Burning Facts, EPA 430-F-06-013; 2006. Available online: https:/ / www.epa.gov/sites/production/files/documents/sunscreen.pdf (accessed on 22 February 2020). 
25. Khazaeli, P.; Mehrabani, M. Screening of Sun Protective Activity of the Ethyl Acetate Extracts of Some Medicinal Plants. Iran. J. Pharm. Res. 2008, 7, 5-9.

26. Gupta, D.; Malawat, T. UV Absorbing Properties of Some Plant Derived Extracts. Res. J. Chem. Sci. 2003, 1, 34-36. 